\title{
Gambaran Maskulinitas Melalui Film (Studi Pandangan Generasi Milenial Pada Tokoh Dilan di Film "Dilan 1990")
}

\author{
Shafira Nusa Kusuma, Wulan Purnama Sari \\ Shafiranusakusuma@gmail.com,Wulanp@fikom.untar.ac.id \\ Fakultas Ilmu Komunikasi Universitas Tarumanagara
}

\begin{abstract}
Through the development of the film industry in Indonesia, local films has benefits to delivering value, illustration, characteristic and many opinions based on their own perception. A film can be a reference for the lifestyle of the community towards the main character in that film. On January 25, 2018, Indonesian produced a film based on novel, which is a true story by Pidi Baiq entitled 'Dilan 1990'. The film received an audience more than 5 million viewers from various circles, especially the millennial generation. Many factors encourage the audience to watch the film, for one of all, how masculinity from the main figure: Dilan. The aims of this research are:1) Knowing the description of Dilan's masculinity in the "Dilan 1990" film to millennial generation audiences, 2) Knowing the millennial generation's view of masculinity. Methods in this research is quantitative with a simple descriptive survey. The results of this research are indicate the millennial generation agreed that character Dilan has a masculine figure, with the dimension "Give em hell" types which shows the highest value, 414.
\end{abstract}

Keywords: Masculinity, Film, Millennial Generation

\begin{abstract}
Abstrak
Melalui perkembangan industri film di Indonesia, film lokal saat ini sudah mulai menjadi wadah penyampaian nilai, bahkan film dapat menjadi acuan gaya hidup pada masyarakat terhadap tokoh yang terdapat dalam film tersebut. Pada 25 Januari 2018 lalu, industri film Indonesia hadir dengan menayangkan film dari novel kisah nyata karya Pidi Baiq yang berjudul "Dilan 1990". Film tersebut mendapatkan jumlah penonton di atas 5 juta penonton dari berbagai kalangan, terutama generasi millenial. Banyak faktor yang mendorong penonton untuk menonton film tersebut, salah satunya adalah gambaran maskulinitas dari sosok Dilan. Tujuan dari penelitian ini adalah: 1) untuk mengetahui gambaran maskulinitas tokoh Dilan pada Film "Dilan 1990" pada penonton generasi milenial, 2) untuk mengetahui sifat maskulinitas tokoh Dilan dari pandangan generasi milenial. Metode penelitian yang digunakan adalah kuantitatif dengan survei sederhana deskriptif. Hasil dari penelitian ini menunjukkan bahwa generasai milenial setuju bahwa tokoh Dilan adalah sosok yang maskulin, dengan dimensi Give em hell yang menunjukkan nilai tertinggi sebesar 414 .
\end{abstract}

Kata Kunci: Maskulinitas, Film, Generasi Milenial 


\section{Pendahuluan}

Pada masa ini, perbedaan maskulin dan feminin pun menggiring anggapan umum bahwa karakteristik maskulin lekat dengan laki-laki, dan karakter ini dikaitkan dengan tiga sifat khusus yaitu kuat, keras, beraroma keringat. Secara sederhana lakilaki dilabeli sifat "macho". Berbicara mengenai maskulinitas, maskulinitas itu sendiri merupakan sebuah konsep yang hadir karena adanya kontruksi sosial terhadap lakilaki. Kontruksi ini pula yang menyebabkan ketika anak laki-laki lahir sudah dibebankan beberapa hal seperti norma, kewajiban dan harapan dari keluarga. Hal ini diturunkan dari generasi ke generasi sehingga seorang laki-laki harus melakukan hal yang telah berlaku bila ingin menjadi lelaki sejati (Demartoto, 2010 dalam Syuhajji, 2017).

Nilai-nilai maskulinitas dapat muncul dengan adanya nilai dari masyarakat itu sendiri, seperti sosok Dilan yang tentu sudah tidak asing lagi di telinga masyarakat. Sosok Dilan mulai terkenal melalui perilaku dan rayuan manis yang dapat membuat para wanita kagum dengan sosoknya. Bukan hanya itu, sosok Dilan juga memperlihatkan sisi laki-laki pada umumnya, yang mudah terbawa emosi dan terkadang sering melakukan tindakan kekerasan. Namun, perilaku yang diperlihatkan Dilan, tidak membuat para penggemarnya kecewa dengan karakter yang dimiliki Dilan. Hal tersebut dapat terlihat dari film "Dilan 1990". Pada 25 Januari 2018 lalu, industri film Indonesia hadir dengan menayangkan film dari novel kisah nyata karya Pidi Baiq yang berjudul "Dilan 1990". Film tersebut sempat bertahan satu bulan lebih di bioskop Indonesia, dan mendapatkan jumlah penonton di atas 5 juta penonton dari berbagai kalangan, antara lain yang lahir pada tahun 90-an, remaja sampai anak-anak usia $13+$ boleh menonton film tersebut. Terkait dengan industri perfilman di Indonesia, film lokal memiliki manfaat sebagai media untuk menyampaikan nilai, gambaran, karakteristik bahkan persepsi yang dapat diterima oleh para penikmat film. Karakteristik tokoh yang terlibat dalam suatu film tersebut juga dapat membentuk suatu gambaran bahkan prilaku terhadap para penikmat film tersebut.

Dalam perkembangannya, perfilman Indonesia saat ini sudah mulai menjadi wadah penyampaian nilai, bahkan, film dapat menjadi acuan gaya hidup pada masyarakat terhadap tokoh yang terdapat dalam film tersebut. Secara tidak langsung, film mengajak masyarakat untuk lebih peka terhadap keadaan di lingkungannya. Melihat kemajuan industri film tersebut, film dapat dikatakan sebagai salah satu media komunikasi karena film dapat menyampaikan pesan kepada masyarakat secara luas. Masyarakat, khususnya generasi milenial sangat mengandalkan adanya kecepatan yang serba instan. Sifat generasi milenial yang menyukai kecepatan teknologi yang serba instan, membuat generasi ini mengandalkan segalanya dengan kebiasaan yang tidak ingin susah dan terkadang menyukai hal-hal yang menyangkut dengan kemajuan teknologi, khususnya media elektronik seperti handphone. Generasi ini lebih mengetahui kemajuan dari media elektronik karena generasi ini tidak bisa menghindar dari kebiasaan mereka yang menyukai teknologi dan selalu berada dekat dengan teknologi. Hal tersebut membuktikan bahwa, generasi milenial akan lebih mengetahui informasi lebih dulu secara cepat melalui media yang mereka gunakan.

Berdasarkan hal tersebut, tidak dapat dipungkiri apabila generasi tersebut dapat disebut sebagai pengusa dari media, khususnya dunia perfilman. Generasi milenial dapat mengetahui perkembangan industri perfilman melalui media dan mereka juga dapat mengakses info film terbaru juga melalui teknologi yang mereka gunakan. 
Kebiasaan generasi milenial tersebut dapat menciptakan ide kreatif yang disukai oleh generasi saat ini yang memiliki pola pikir yang sama, berbeda dengan generasi sebelumnya yang tentu pola pikirnya tidak sekreatif generasi milenial yang lebih mengetahui kemajuan teknologi lebih dalam. Maka dari itu, generasi milenial dapat menilai bahkan membuat persepi tentang apa yang disampaikan oleh media massa, termasuk menilai apa gambaran maskulinitas dari sosok Dilan di dalam film "Dilan 1990".

Berdasarkan uraian di atas, peneliti tertarik untuk meneliti gambaran maskulinitas tokoh Dilan dalam Film "Dilan 1990" pada penonton generasi milenial. Peneliti akan menganalisis penonton generasi millenial terhadap pandangan maskulinitas tokoh Dilan, sehingga peneliti dapat mengetahui bagaimana gambaran maskulinitas tokoh Dilan dari penonton generasi milenial.

Rumusan Masalah: Apa gambaran maskulinitas tokoh Dilan dalam Film "Dilan 1990" pada penonton generasi milenial? Apa sifat maskulinitas tokoh Dilan dari pandangan generasi milenial? Penelitian ini bertujuan untuk mengetahui gambaran maskulinitas tokoh Dilan pada Film "Dilan 1990" pada penonton generasi milenial, dan mengetahui sifat maskulinitas tokoh Dilan dari pandangan generasi milenial.

Definisi komunikasi massa yang paling sederhana dikemukakan oleh Bittner (Ardianto, 2007), yakni: komunikasi massa adalah pesan yang dikomunikasikan melalui media massa pada sejumlah besar orang (mass communication is messages communited through a mass medium to a large number of people), dari definisi tersebut dapat diketahui bahwa komunikasi massa itu harus menggunakan media massa. Sementara, film adalah gambar hidup, hasil dari seonggok seluloid, yang diputar dengan menggunakan proyektor dan ditembakkan ke layar, yang dipertunjukkan di gedung bioskop (Romli, 2016). Film bermula pada akhir abad ke19 sebagai teknologi baru, tetapi konten dan fungsi yang ditawarkan masih sangat jarang. Film kemudian berubah menjadi alat presentasi dan distribusi dari tradisi hiburan yang mampu menjangkau populasi dalam jumlah besar dengan cepat, bahkan di wilayah pedesaan (McQuail 2011).

Menurut Nasir (2007) dalam (Dermatoto 2010) Maskulin atau maskulinitas diambil dari bahasa Perancis "macculinine". Maskulinitas merupakan karakter gender yang secara sosial dilekatkan pada sosok laki-laki. Sebagai kontruksi sosial maksulinitas bahkan telah ditanamkan dalam keluarga melalui doktrin yang diberikan oleh orang tua. Maskulinitas merupakan konstruksi dari budaya dan masyarakat. Setiap budaya memahami maskulinitas secara beda-beda (Marcella, 2005).

Aderson dalam artikelnya "Inclusive Masculinity Theory and Gendered Politics of Men"es Rugby" (2010) mengutip dari Pronger dua jenis maskulinitas: pertama adalah makulinitas orthodox. Maskulinitas jenis ini memiliki ciri-ciri homophobia, misogyny, bersifat fisik, dan berkeberanian. Berikutnya adalah maskulinitas insklusive (inclusive masculinity) yang tidak memiliki sifat-sifat seperti maskulinitas orthodox. Menurut Connell $(1987,1995)$ beberapa jenis maskulinitas bisa muncul dalam suatu organisasi, institusi, atau masyarakat, tetapi ketika membicarakan hegemoni hanya akan ada satu maskulinitas yang dominan. Dengan kata lain, pemicu munculnya maskulinitas itulah yang akan menentukan bentuk maskulinitas yang dominan. Semisal jika pemicunya homophobia, maskulinitas orthodokslah yang akan muncul. Dengan demikian, jika tren homophobia itu menurun, maskulinitas yang dominan bukan lagi yang orthodoks. Dalam hal ini maskulinitas inklusif yang ditawarkan oleh Anderson menyatakan bahwa banyak 
jenis maskulinitas yang muncul seiring melunturnya homophobia. Bahkan, ketika hegemoni tersebut menjadi hilang maka tidak akan muncul lagi maskulinitas yang dominan (Anderson, 2005 dalam Hidayatullah, 2013).

Media merupakan salah satu sarana yang berperan dalam pencitraan maskulinitas. Melalui berbagai media berbagai pihak berupaya memberikan gambaran mengenai konsep maskulinitas. Hal itu seperti dilakukan beynon dalam Nasir (2007) dalam (Dermatoto 2010) yang melakukan kajian mengenai konsep maskulinitas melalui berbagai hal, terutama media. Berbagai media yang dijadikan sebagai objek kajian mengenai maskulinitas diantarana: karya sastra, media cetak, media siar, media Visual dan Performatif, Autobiografi/Biografi dan Dokumentasi, dan etnografi.

Dari masa ke masa, konsep maskulinitas telah mengalami perkembangan. Menurut Beynon dalam jurnal Demartoto, Konsep Maskulinas dari Jaman ke Jaman dan Citranya dalam Media, Maskulinitas mengalami perubahan setiap 4 dekade waktu. Yaitu maskulin sebelum tahun 1980-an, tahun 1980-an, tahun 1990-an, dan maskulin pada tahun 2000-an. Berdasarkan keempat kelompok tersebut, dapat ditarik sifat-sifat maskulinitas seperti berikut: No Sissy Stuff (Tidak kewanita-wanitaan), Be a Big Wheel (Berpengaruh penting), Be a Sturdy Oak (Kuat), Give em Hell (Berani), new Man as Nurturer (Kebapakan), New Man as Narcissist (Narsistik), Sifat kelakilakian yang macho, kekerasan dan hooliganism (Sangar), laki-laki metroseksual mengagungkan fashion.

Gen Y atau millennials (1977-1997), menurut Sugihartati (2014) dalam Taufan (2017) ini dilahirkan antara 1977-1997. Menurut Prasetyanti \& Prasetyo (2017) dalam Taufan (2017). Generasi millennial merupakan generasi modern yang aktif bekerja, penelitian, dan berpikir inovatif tentang organisasi, memiliki rasa optimisme dan kemauan untuk bekerja dengan kompetitif, terbuka, dan fleksibel.

\section{Metode Penelitian}

Pendekatan yang dilakukan oleh peneliti adalah pendekatan kuantitatif dengan strategi penelitian survei deskriptif. Populasi dalam penelitian ini adalah penonton "Dilan 1990" yang lahir pada tahun 1977-1997 dan berdomisili di Jabodetabek. Sedangkan, untuk pemilihan sampel, penulis mengambil 130 responden, kelahiran 1977-1997, yang sudah pernah menonton film "Dilan 1990" dan berdomisili di Jabodetabek. Metode pengumpulan data yang digunakan penulis adalah dengan menyebar kuisioner kepada 130 responden, jurnal ilmiah, dan buku komunikasi.

Teknik pengolahan data yang digunakan penulis adalah editing, koding, tabulasi dan analisis data, analisis data yang digunakan penulis adalah dengan mencari nilai mean dari hasil penelitian. Penulis menggunakan skala likert guna menjadi instrument perhitungn dalam penelitian yang diangkat. Untuk teknik keabsahan data dalam penelitian ini, peneliti menggunakan pengujian validitas dan reliabilitas, yang dimana pengujian validitas digunakan untuk mencari ketepatan antara data yang terkumpul dengan data yang sesungguhnya terjadi pada obyek yang diteliti. Sedangkan untuk hasil penelitian yang reliabel, apabila terdapat kesamaan data dalam waktu yang berbeda. Penulis melakukan Pre-Test untuk 30 responden Post-Test untuk 100 responden berikutnya. 


\section{Hasil Temuan dan Diskusi}

Pre Test (Validitas \& Reliabilitas 1)

Validitas variabel gambaran maskulinitas film "Dilan 1990" diuji dengan membandingkan nilai dalam Tabel Corrected Item Total Correlation dengan R-Tabel yang ditentukan sesuai dengan jumlah sampel yang diambil (30 responden) untuk data Pre-Test yaitu sebesar 0,349. Sehingga hasil yang didapat adalah sebanyak 8 pernyataan dalam variabel lebih kecil dari R-Tabel, Sedangkan, seluruh item lainnya lebih besar dari R-Tabel. Artinya, 16 pertanyaan lainnya, digunakan dalam variabel gambaran maskulinitas.

Uji Reliabilitas variabel gambaran umum maskulinitas film "Dilan 1990" memperlihatkan bahwa nilai Cronbach"es Alpha sebesar 0,810 ternyata lebih besar dari R-Tabel sebesar 0,349 yang artinya data dari variabel tersebut adalah reliabel.

Post Test (Validitas \& Reliabilitas 2)

Dari hasil validitas-1 dapat dilihat bahwa masih ada pertanyaan yang tidak valid sebanyak delapan butir pertanyaan. Maka dilakukan uji validitas ke dua dengan membuang butir pertanyaan yang tidak valid dan dianalisis kembali. Jumlah sampel yang diambil untuk Post-Test sebanyak 100 responden, sehingga R-Tabel yang digunakan sebesar 0,194. Hsil yang didapat dari uji validitas ke-2 diperoleh 16 butir pertanyaan yang keseluruhan datanya sudah valid, sehingga 16 pertanyaan tersebut dapat digunakan dalam variabel gambaran maskulinitas tokoh Dilan dalam film "Dilan 1990" pada penonton generasi milenial.

Uji Reliabilitas variabel gambaran umum maskulinitas film "Dilan 1990" memperlihatkan bahwa nilai Cronbach "s Alpha, bernilai 0,858 lebih besar dari RTabel sebesar 0,194 yang artinya data dari variabel tersebut adalah reliable. Kesimpulan variabel gambaran maskulinitas dapat digunakan untuk uji hipotesis.

\section{Hasil Skala Likert}

Skala likert pada penelitian ini digunakan untuk mengukur pandangan generasi milenial terhadap maskulinitas tokoh Dilan dalam film "Dilan 1990". Skala likert sebanyak 5 tingkat, yaitu sangat tidak setuju, tidak setuju, netral, setuju dan sangat setuju. Setiap masing-masing jawaban memiliki skor, untuk jawaban sangat tidak setuju memiliki skor 1, tidak setuju memiliki skor 2, netral memiliki skor 3, setuju memiliki skor 4 dan sangat setuju memiliki skor 5 .

Tabel 1. Total Skor seluruh Pernyataan Gambaran Maskulinitas Tokoh Dilan dalam Film "1990"

\begin{tabular}{ccc}
\hline & Pernyataan \\
Jawaban & Jumlah & Persentase \\
\hline SS & 2 & 13 \\
S & 7 & 44 \\
N & 6 & 38 \\
TS & 1 & 6,3 \\
STS & 0 & 0 \\
\hline
\end{tabular}

Sumber: Data Primer, diolah (2018)

Melalui penjelasan di atas, membuktikan bahwa film memiliki peran penting 
dalam memberi pendapat bagi masyarakat khususnya generasi milenial. Film juga dapat menjadi media yang dijadikan sebagai objek kajian mengenai maskulinitas, terutama untuk generasi milenial. Dari hal tersebut, banyak generasi milenial yang setuju dengan nilai maskulinitas yang dimiliki Dilan dari fisik maupun prilaku yang terlihat dalam film "Dilan 1990", hal ini dapat terlihat dari hasil pernyataan dalam kuisioner yang diberikan kepada 100 generasi milenial dengan 16 pernyataan. Hasil kuisioner tersebut, memperlihatkan bahwa jumlah persentase kategori setuju sampai sangat setuju lebih besar dibandingkan persentase kategori tidak setuju sampai sangat tidak setuju. Nilai persentase netral 38\%, setuju sebesar $44 \%$ dan sangat setuju $13 \%$, sedangkan nilai tidak setuju sebesar $6,3 \%$, dan sangat tidak setuju sebesar 0\%. Maka dari itu, persentase terbesar terlihat dari kategori "setuju" dengan pendapat bahwa Dilan adalah sosok yang maskulin sebesar $44 \%$ responden. Bagi para generasi milenial yang sudah menonton film tersebut, mereka dapat menilai dan mengetahui karakteristik tokoh Dilan secara lebih detail.

Nilai Mean

Tabel 2. Nilai Mean dari Dimensi Maskulinitas Sumber: Data Primer, diolah (2018)

\begin{tabular}{cc}
\hline Dimensi & Nilai Mean \\
\hline 1 & 388,5 \\
2 & 390,3 \\
3 & 335 \\
4 & 414 \\
5 & 352,5 \\
6 & 272 \\
7 & 350,5 \\
8 & 368 \\
\hline
\end{tabular}

Setelah mengetahui bahwa Dilan adalah sosok yang maskulin, peneliti ingin mengetahui sifat maskulin apa yang dimiliki sosok Dilan dalam film "Dilan 1990". Maka dari itu, peneliti menganalisis data mean untuk mengetahui sifat maskulin yang dimiliki tokoh Dilan. Peneliti memberikan 16 pernyataan kepada 100 responden yang masing-masing pernyataan memiliki sifat dari ke-8 dimensi maskulinitas. Hasil perhitungan analisis data mean dapat dilihat dari tabel 2 .

Dari hasil penelitian nilai mean, dapat terlihat sifat maskulin yang dimiliki Dilan. Hasil tersebut, menunjukkan bahwa sifat maskulin yang Dimiliki Dilan adalah Give em Hell yang merupakan dimensi ke-4 dari 8 dimensi. Nilai mean dari dimensi tersebut menunjukkan nilai mean tertinggi sebesar 414, dibandingkan dengan dimensi yang lain. Pengertian dari dimensi Give em hell sendiri, yaitu laki-laki yang mempunyai aura keberanian dan agresi (tindakan merusak, menyengsarakan dan membahayakan objek manusia atau kelompok tertentu), serta harus mampu mengambil risiko walaupun alasan dan rasa takut menginginkan sebaliknya. Dapat dilihat juga, dari hasil penjelasan diatas yang menunjukkan bahwa Dilan termasuk ke dalam dimensi maskulin ke-4, dan dimensi tersebut terdapat nilai "keberanian". Maka, Dilan termasuk ke dalam jenis maskulinitas orthodox. 


\section{Simpulan}

Berdasarkan hasil penelitian dan pembahasan yang telah dilakukan oleh peneliti dengan menyebarkan kuisioner kepada 100 generasi milenial, dapat disimpulkan bahwa Dilan adalah sosok yang maskulin, hal tersebut dilihat dari hasil persentase total skor seluruh penyataan sebesar $44 \%$ yang menjawab menjawab setuju. Dari hasil pembahasan juga dapat terlihat nilai dari dimensi Give em Hell memiliki nilai mean terbesar dibandingkan dimensi maskulinitas lainnya. Maka dari hal tersebut, dapat disimpulkan bahwa gambaran maskulinitas tokoh Dilan dalam film "Dilan 1990" adalah sosok maskulin yang memiliki keberanian dan agresi (tindakan merusak, menyengsarakan dan membahayakan objek manusia atau kelompok tertentu), serta harus mampu mengambil risiko walaupun alasan dan rasa takut menginginkan sebaliknya. Dari hasil penelitian dan pembahasan yang telah dilakukan. Adapun kesimpulan yang didapat dari penelitian tersebut. Setelah menyebarkan kusioner kepada 100 responden, dengan 16 pernyataan mengenai maskulinitas tokoh Dilan. Maka, analisis penonton generasi milenial terhadap pandangan maskulinitas tokoh Dilan yang diperoleh responden adalah sebesar $44 \%$ setuju bahwa Dilan adalah sosok yang maskulin.

Maskulinitas juga memiliki 8 dimensi lainnya. Sehingga peneliti juga ingin mengetahui apa sifat (dimensi) maskulinitas yang dimiliki tokoh Dilan dari pandangan generasi milenial. Dari hasil nilai mean untuk mencari sifat maskulinitas Dilan, maka dimensi ke-4 (Give em Hell) memiliki nilai mean tertinggi, sebesar 414, dibandingkan dimensi yang lain. Dimensi give em Hell sendiri, memiliki nilai "keberanian" didalamnya, maka dari itu, Dilan termasuk ke dalam kenis masulinitas orthodox.

\section{Ucapan Terima Kasih}

Dalam penelitian ini, penulis mengucapkan terima kasih sebesar-besarnya kepada, Ibu Wulan Purnama Sari, S.I.Kom., M.Si. selaku dosen pembimbing, Kedua orang tua dan keluarga penulis, Alya Nindityas selaku sahabat penulis, dan Shafira Fauzi, Amelia, Ribka, Ariyanisa selaku teman seperjuangan penulis.

\section{Daftar Pustaka}

Akbar, Taufan T., \& Alphana ChristyFalopenia. (2017). Personal Image Generasi Millennial Korban Cyberbullying pada akun Instagram dan Ask FM di Jakarta. Prosiding Konferensi Nasional Komunikasi. 1(1): 373-374.

Ardianto, dkk. (2007). Komunikasi Massa. Bandung: Refika Offset.

Danial Hidayatullah. (2013). Maskulinitas, Kekerasan, dan Negara dalam Film The Raid: Redemption. E-journal UIN. 12(2): 233-234.

Demartoto, Argyo. (2010). Konsep Maskulinitas dari Jaman ke Jaman dan Citranya dalam Media. Jurnal Jurusan Sosiologi Fakultas Ilmu Sosial dan Ilmu Politik UNS Surakarta. Hal: 1-8.

Marcella. (2005). Representasi Maskulinitas pada Iklan Memasak (Analisis Semiotika: Pada Iklan kecap sedaap versi Ayah Jago Masak). Skripsi. Universitas Tarumanagara.

McQuail. (2011). Teori Komunikasi Massa. Jakarta: Penerbit Salemba Humanika.

Romli, Khomsahrial. (2016). Komunikasi Massa. Jakarta: Gransindo. 
Syulhajji S. (2017). Representasi Maskulinitas dalam Film Talak 3 (Studi Analisis Semiotika Roland Barthes). E-Journal Ilmu Komunikasi. 5(2): 2. 